\title{
Timing and efficacy of transmitter release at mossy fiber synapses in the hippocampal network
}

\author{
Josef Bischofberger • Dominique Engel • \\ Michael Frotscher • Peter Jonas
}

Received: 29 March 2006 / Accepted: 18 April 2006 / Published online: 27 June 2006

(C) Springer-Verlag 2006

\begin{abstract}
It is widely accepted that the hippocampus plays a major role in learning and memory. The mossy fiber synapse between granule cells in the dentate gyrus and pyramidal neurons in the $\mathrm{CA} 3$ region is a key component of the hippocampal trisynaptic circuit. Recent work, partially based on direct presynaptic patch-clamp recordings from hippocampal mossy fiber boutons, sheds light on the mechanisms of synaptic transmission and plasticity at mossy fiber synapses. A high $\mathrm{Na}^{+}$channel density in mossy fiber boutons leads to a large amplitude of the presynaptic action potential. Together with the fast gating of presynaptic $\mathrm{Ca}^{2+}$ channels, this generates a large and brief presynaptic $\mathrm{Ca}^{2+}$ influx, which can trigger transmitter release with high efficiency and temporal precision. The large number of release sites, the large size of the releasable pool of vesicles, and the huge extent of presynaptic plasticity confer unique strength to this synapse, suggesting a large impact onto the CA3 pyramidal cell network under specific behavioral conditions. The characteristic properties of the hippocampal mossy fiber synapse may be important for pattern separation and information storage in the dentate gyrus-CA3 cell network.
\end{abstract}

\footnotetext{
J. Bischofberger $\cdot$ D. Engel $\cdot$ P. Jonas $(\bowtie)$

Physiologisches Institut der Universität Freiburg,

Hermann-Herder-Str. 7,

D-79104 Freiburg, Germany

e-mail: peter.jonas@physiologie.uni-freiburg.de
}

\section{Frotscher}

Institut für Anatomie und Zellbiologie der Universität Freiburg,

Albertstr. 17,

D-79104 Freiburg, Germany
Keywords Presynaptic recording · Mossy fiber boutons . Mossy fiber synapses · Hippocampus · Autoassociative networks $\cdot$ Episodic memory $\cdot$ Synaptic efficacy

\section{The mossy fiber synapse: a key connection in the hippocampal network}

The hippocampal formation consists of three types of principal neurons: granule cells in the dentate gyrus, CA3 pyramidal cells, and CA1 pyramidal neurons. These cells are interconnected by glutamatergic synapses, forming the classical trisynaptic circuit (Fig. 1a,b). Dentate gyrus granule cells receive excitatory glutamatergic input from layer 2 pyramidal cells of the entorhinal cortex and project to CA3 pyramidal cells. CA3 pyramidal cells project to CA1 cells, which in turn project to the subiculum and back to the entorhinal cortex [4]. In addition to this trisynaptic circuit, there is also a direct input from the entorhinal cortex to both CA3 and CA1 pyramidal cells. Furthermore, CA3 pyramidal neurons are extensively connected to each other via recurrent collateral synapses.

The nonmyelinated axons of the granule cells, the socalled mossy fibers, show several structural properties that distinguish them from the other synaptic pathways [39]. They project to the CA3 region, mainly traveling within a narrow band termed "stratum lucidum." Several $(\sim 15)$ large "giant" boutons ( $\sim 3-5-\mu \mathrm{m}$ diameter) emerge from a single mossy fiber axon, either arranged in an en passant manner or attached to the main axon via a short perpendicular axonal branch [1, 8, 29, 31] (Fig. 1c,d). A large mossy fiber bouton typically contacts only a single CA3 pyramidal neuron [21], and a mossy fiber axon contacts a given CA3 pyramidal neuron only once, as boutons are $\sim 150 \mu \mathrm{m}$ apart. As the rat hippocampus contains $\sim 1$ million granule cells 

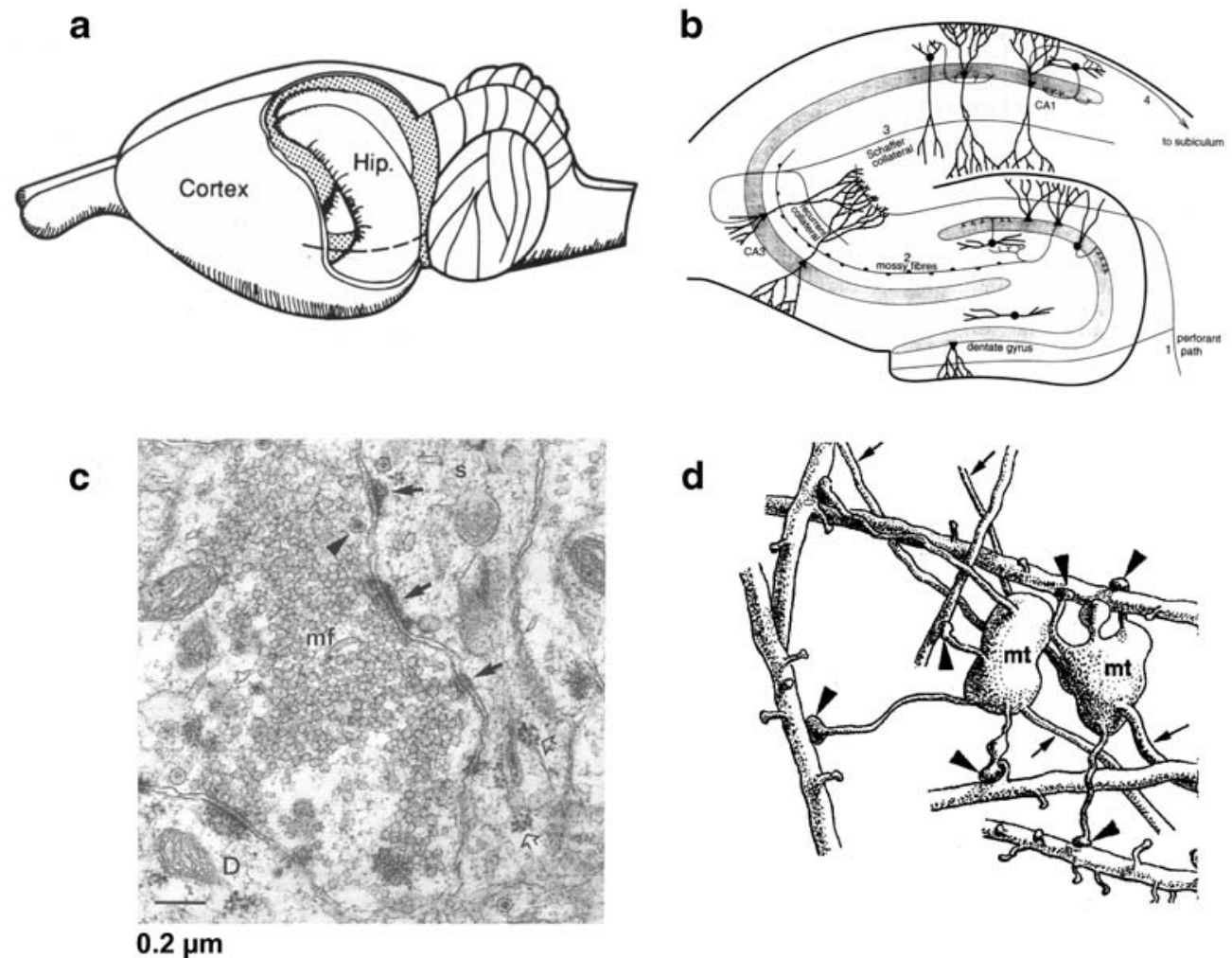

Fig. 1 Anatomical position of mossy fiber synapses in the hippocampal formation. a Macroscopic anatomy of the hippocampus in rat brain. The neocortex was fenestrated to show the location of the underlying hippocampal formation. b Schematic diagram of the trisynaptic circuit of the hippocampus. The major components are: perforant path-dentate gyrus granule cells-mossy fibers-CA3 pyramidal neurons-Schaffer collaterals-CA1 pyramidal neurons-subiculum. c Electron micrograph of a large hippocampal mossy fiber bouton in stratum lucidum of the

and $~ 300,000$ CA3 pyramidal neurons (per hippocampus; [4]), and as a single granule cell contacts $\sim 15$ CA3 pyramidal neurons, a single CA3 pyramidal neuron on average receives input from $\sim 15 \times 1,000,000 / 300,000=50$ granule cells. Thus, the mossy fiber-CA3 pyramidal neuron synapse forms a sparse connection.

In addition to the large boutons on CA3 pyramidal neurons, the mossy fiber forms three other types of synaptic terminals, contacting distinct postsynaptic target cells. (1) Large boutons emerging from hilar collaterals $(\sim 15$ per mossy fiber axon) form synapses on glutamatergic hilar mossy cells [1]. Mossy cells, in turn, establish an excitatory feedback circuit by forming synapses on granule cells of the ipsilateral dentate gyrus and on granule cells of the contralateral side. (2) Filopodial extensions emerging from large mossy fiber boutons ( 2.5 filopodia per large bouton, [1]) form synapses on GABAergic interneurons in the stratum lucidum $[1,81]$ (Fig. 1d). In addition, large mossy fiber boutons can contact the dendritic shafts of GABAergic interneurons in the stratum lucidum directly [29]. (3) Small boutons emerging from the main axon $(\sim 15)$ or
CA3 region. $m f$ Mossy fiber bouton, $s$ spine, $D$ dendrite (of CA3 pyramidal neuron). Arrows indicate synaptic membrane specializations, arrowhead points to large dense-core vesicle, and open arrows indicate ribosomes at the spine base. Electron micrograph taken from Frotscher [30]. d Schematic illustration of two mossy fiber boutons. Arrows indicate mossy fiber axons, arrowheads show filopodial extensions, which contact interneuron dendrites. Illustration from Acsády et al. [1], with permission of the Society for Neuroscience, copyright (1998)

from hilar collaterals ( 150 per mossy fiber axon) form synapses on GABAergic interneurons in the stratum lucidum and the hilus [1]. Thus, the total number of synapses formed on GABAergic interneurons (in CA3 and hilus) via filopodial extensions and small boutons greatly exceeds the total number of synapses formed on glutamatergic neurons (CA3 pyramidal neurons and mossy cells) via large boutons [1].

\section{Presynaptic action potential and voltage-gated $\mathrm{Na}^{+}$ and $\mathrm{K}^{+}$channels in hippocampal mossy fiber boutons}

After the development of methods for patch-clamp recording in brain slices $[26,38]$, techniques were gradually refined to a point when it became possible to obtain recordings from presynaptic elements, including mossy fiber boutons [12, $28,34]$. The key steps of improvement were as follows: (1) the enhanced visibility provided by high-numerical aperture objectives and infrared illumination [75]; (2) the development of vibratomes with minimal blade vibration in the 


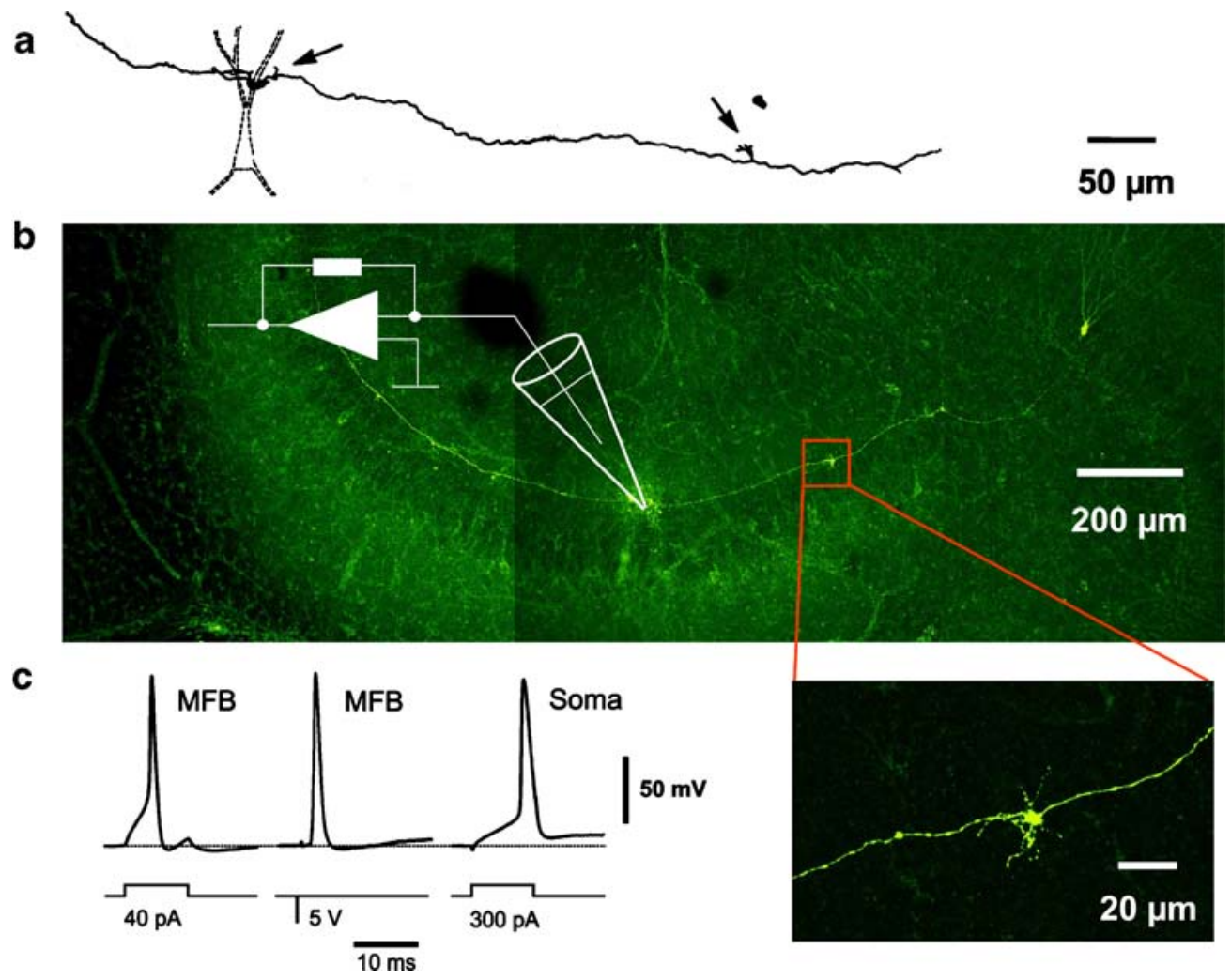

Fig. 2 Direct patch-clamp recording from hippocampal mossy fiber terminals. a Hippocampal mossy fiber bouton, filled with biocytin during whole-cell recording, stained with avidin-horseradish peroxidase complex, and reconstructed using a camera lucida. Arrows show the recorded bouton (left) and an adjacent bouton emerging from the same axon (right). Image from N. Spruston and P. Jonas (1993), unpublished. b Hippocampal mossy fiber bouton, filled with biocytin during whole-cell recording, stained using Alexa-conjugated avidin, and examined with a confocal laser scanning microscope. The

vertical direction, resulting in an improved preservation of superficial tissue layers [34], although mossy fiber terminal recordings with commercially available tissue slicers were also reported [72]; (3) the use of sucrose-based cutting solutions with reduced $\mathrm{Na}^{+}$and $\mathrm{Ca}^{2+}$ concentrations, which further improves tissue preservation during cutting and maintenance of slices [34]. Collectively, these refinements made it possible to routinely obtain patch-clamp recordings from large hippocampal mossy fiber boutons in the stratum lucidum [6, 27, 33, 37].

Direct patch-clamp recording allowed us, for the first time, to examine the presynaptic action potential that triggers glutamate release at a cortical glutamatergic synapse (Fig. 2). Kinetic analysis revealed that the presynaptic action potential was very brief, with a half-duration of $915 \mu \mathrm{s}$ at $22^{\circ} \mathrm{C}$ and $380 \mu \mathrm{s}$ at $34^{\circ} \mathrm{C}[6,33]$. A comparison of action potentials in mossy fiber boutons with those in granule cell somata revealed that the time course of the presynaptic action potential was $\sim$ two times faster than that of the somatic action potential in the same cell type $[6,33]$ (Fig. 2c). Thus, the properties of the presynaptic action potential are highly recorded bouton is indicated by the attached schematic pipette. The square box indicates the adjacent bouton, shown at higher magnification in the inset. The granule cell soma is visible on the right. Image form G. Stocca and J. Bischofberger, unpublished. c Presynaptic action potentials in mossy fiber boutons evoked by direct current injection (left) and extracellular stimulation of the axon (middle). The action potential recorded in a granule cell soma is shown for comparison $(r i g h t)$. Note that the presynaptic action potential is two times briefer than the somatic action potential. Data from Bischofberger et al. [6]

specialized. Brief presynaptic spikes may ensure the synchrony of transmitter release at mossy fiber synapses.

The characteristic properties of the presynaptic action potential in hippocampal mossy fiber boutons are conferred by the expression of a distinct set of voltage-gated ion channels. Voltage-clamp analysis revealed that several types of voltage-gated channels are expressed in hippocampal mossy fiber boutons. First, these boutons contain a high density of voltage-gated $\mathrm{Na}^{+}$channels [27]. Estimates based on outside-out patch recordings suggested that the $\mathrm{Na}^{+}$conductance density was $\sim 50 \mathrm{mS} \mathrm{cm}{ }^{-2}$, corresponding to $\sim 40$ channels $\mu \mathrm{m}^{-2}$ and $\sim 2,000$ channels per typically sized bouton. The $\mathrm{Na}^{+}$channel density in hippocampal mossy fiber boutons is comparable to previously reported $\mathrm{Na}^{+}$channel densities in peripheral axons [41, 42]. Thus, mossy fiber boutons have axon-like properties. Immunocytochemical studies showed a high level of Nav1.2 immunoreactivity in the mossy fiber tract [83]. Furthermore, Nav1.2 and Nav1.6 immunoreactivity are often colocalized in nonmyelinated axons throughout the entire brain [18]. This suggests that native presynaptic channels in mossy fiber 
boutons are assembled from either Nav1.2 or Nav1.2/ Nav1.6 alpha subunits.

Mossy fiber boutons also express functionally specialized voltage-gated $\mathrm{K}^{+}$channels [33]. These channels show low activation threshold, relatively fast inactivation, and are blocked by external tetraethylammonium ions (TEA) and dendrotoxin (a toxin from the green mamba, which blocks $\mathrm{K}^{+}$channels assembled from Kv1.1, 1.2, and 1.6 subunits). These functional and pharmacological properties of the presynaptic $\mathrm{Kv}$ channels greatly constrain their subunit composition. The low activation threshold and the sensitivity to TEA and dendrotoxin suggest that the presynaptic channel is assembled from Kv1 subunits. Furthermore, the fast inactivation suggests that the presynaptic channel contains either Kv1.4 subunits or Kvbeta subunits. Consistent with this hypothesis, Kv1.1, Kv1.4, and Kvbeta immunoreactivity is found in the mossy fiber tract [22, 69]. Thus, the results suggest that the native $\mathrm{K}^{+}$channel in mossy fiber buotons is a $\mathrm{Kv} 1.1 / \mathrm{Kv} 1.4$ heteromer or a $\mathrm{Kv} 1.1$ alpha/beta subunit heteromer [33].

Are hippocampal mossy fibers involved in information processing [23]? Or do they follow the rule, "The axon does not think. It only ax." [7]? Experimental evidence suggests that the propagation of action potentials in mossy fiber axons is reliable, in both the orthodromic [6] and the antidromic direction [70, 72]. Furthermore, simulation of action potential propagation in mossy fiber boutons showed that the experimentally determined $\mathrm{Na}^{+}$conductance density of $50 \mathrm{mS} \mathrm{cm}$, if homogeneously implemented in boutons and axons, provides a high safety factor of action potential propagation [27]. These findings suggest that mossy fiber axons are reliable transmission devices.

However, two lines of evidence suggest that mossy fiber axons are also capable of information processing. First, the duration of the presynaptic action potential is not constant, but shows broadening during repetitive stimulation [33]. Action potential broadening is much more pronounced in mossy fiber boutons than in the calyx of Held in the auditory brainstem [11], implying that broadening is a specific property of cortical presynaptic terminals. This may suggest that information in the mossy fiber system is not only coded by action potential frequency and timing but also as action potential duration [25]. Second, recent experiments revealed that subthreshold excitatory postsynaptic potentials (EPSPs) can be passively propagated from the somatodendritic domain of granule cells to mossy fiber boutons [2]. This may suggest that information in the mossy fiber system is coded by both action potential ("digital") and subthreshold ("analogue") signals. Both spike duration coding and analogue coding may enrich the computational repertoire of mossy fiber axons.

\section{Action potential-exocytosis coupling in hippocampal mossy fiber boutons}

As in many other synapses, exocytosis at hippocampal mossy fiber boutons requires the opening of voltage-gated presynaptic $\mathrm{Ca}^{2+}$ channels. Voltage-clamp analysis of $\mathrm{Ca}^{2+}$ currents in hippocampal mossy fiber boutons revealed that the presynaptic $\mathrm{Ca}^{2+}$ channels show a high activation threshold [6]. $\mathrm{Ca}^{2+}$ currents recorded in mossy fiber boutons are largely blocked by the selective $\mathrm{Ca}^{2+}$ channel blockers $\omega$-agatoxin IVa and $\omega$-conotoxin GVIa, suggesting that they are of the P/Q-type (Cav2.1) and N-type (Cav2.2; [5]) Evoked mossy fiber-CA3 pyramidal neuron excitatory postsynaptic currents (EPSCs) are also reduced by $\omega$-agatoxin and $\omega$-conotoxin, demonstrating that both $\mathrm{P} / \mathrm{Q}-$ and N-type channels couple to glutamate release [19]. Thus, converging evidence suggests that synaptic transmission at the mossy fiber-CA3 synapse is mediated by P/Qand N-type $\mathrm{Ca}^{2+}$ channels. $\mathrm{Ca}^{2+}$-imaging experiments recently suggested the presence of R-type $\mathrm{Ca}^{2+}$ channels in a subset of hippocampal mossy fiber boutons [59]. It remains to be shown whether these findings can be confirmed in direct recordings and what role R-type $\mathrm{Ca}^{2+}$ channels play in mossy fiber synaptic transmission [16, 32].

Analysis of the gating kinetics of the presynaptic $\mathrm{Ca}^{2+}$ channels revealed that both activation and deactivation of the presynaptic $\mathrm{Ca}^{2+}$ channels are fast, with time constants in the submillisecond range [6] (Fig. 3). As a consequence, the presynaptic $\mathrm{Ca}^{2+}$ channels are activated very efficiently during the rising phase of the presynaptic action potential. Maximal activation occurs shortly after the peak of the action potential. However, little $\mathrm{Ca}^{2+}$ current is flowing at that time because the driving force is small (Fig. 3a,b). During action potential repolarization, the driving force for $\mathrm{Ca}^{2+}$ current flow increases rapidly. However, concurrently the $\mathrm{Ca}^{2+}$ channels begin to deactivate. The temporally overlapping processes of changes in driving force and channel deactivation result in an approximately symmetrical $\mathrm{Ca}^{2+}$ current with short half-duration $\left(570 \mu\right.$ s at $22^{\circ} \mathrm{C}$ and $170 \mu \mathrm{s}$ at $34^{\circ} \mathrm{C}$ ) and large amplitude. The peak of the current occurs in the center of the repolarization phase $[6$, 33]. Detailed computational analysis of $\mathrm{Ca}^{2+}$ channel gating in hippocampal mossy fiber boutons further suggested that the gating kinetics of activation and deactivation are optimized to generate a maximal $\mathrm{Ca}^{2+}$ inflow during a minimal period of time (Fig. 3c,d). Optimized $\mathrm{Ca}^{2+}$ channel gating will be important for efficacy and synchrony of transmitter release. Remarkably, the sequence of rapid activation and deactivation of presynaptic $\mathrm{Ca}^{2+}$ channels in mossy fiber boutons shows many similarities to the calyx of Held, which plays a key role in temporal signal processing in the auditory brainstem [10-12]. 
a

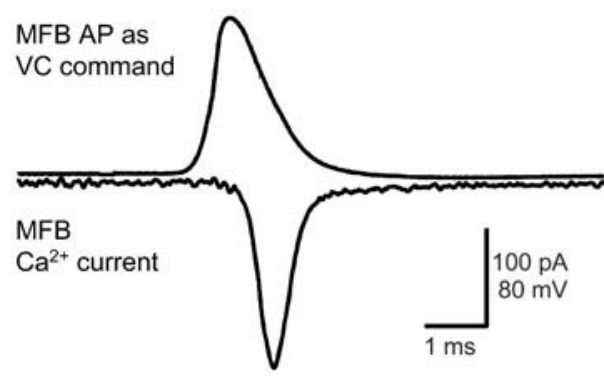

C
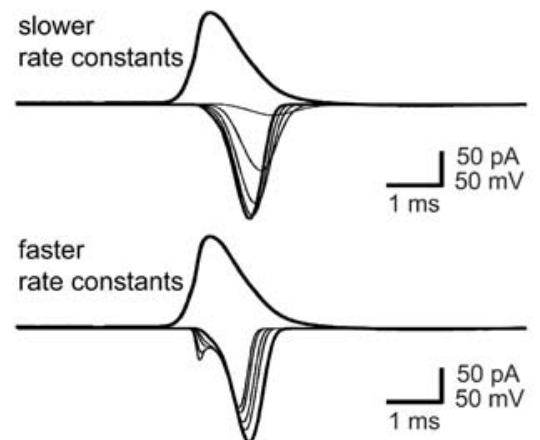

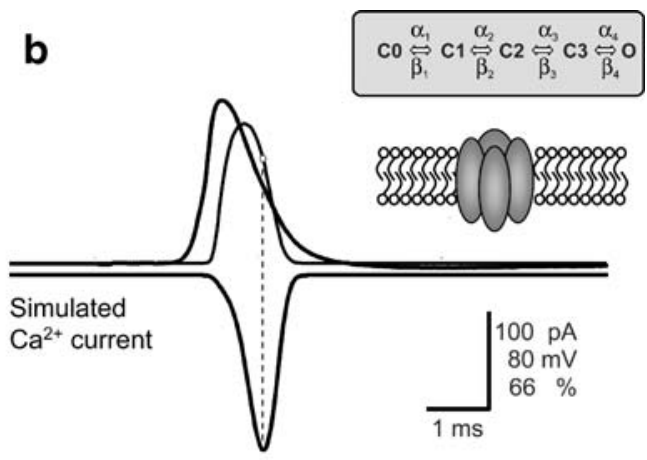

d

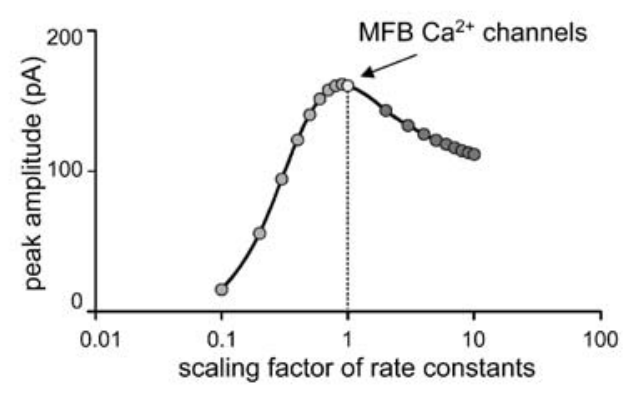

with altered gating properties by presynaptic action potential waveforms. Slowing of gating (upper traces; factors 2-10) reduces the peak amplitude of the $\mathrm{Ca}^{2+}$ current. Acceleration of gating (lower traces; factors $0.9-0.1$ ) reduces the $\mathrm{Ca}^{2+}$ current and leads to a biphasic $\mathrm{Ca}^{2+}$ current for large changes. d Plot of action potential-evoked $\mathrm{Ca}^{2+}$ current peak amplitude against scaling factor of the rates. The physiological value of the rates corresponds to a scaling factor of 1 (vertical dashed line). Data from Bischofberger et al. [6]

applied intracellularly $(10 \mathrm{mM})$ completely blocks transmission at granule cell autapses [79]. Thus, the distance between $\mathrm{Ca}^{2+}$ source and $\mathrm{Ca}^{2+}$ sensor might be relatively large. In conclusion, the available data are consistent with the view that transmitter release at hippocampal mossy fiber synapses is triggered by a large number of presynaptic $\mathrm{Ca}^{2+}$ channels, which might result in a precisely timed presynaptic $\mathrm{Ca}^{2+}$ signal even in the presence of stochastic single channel gating. However, the distance between $\mathrm{Ca}^{2+}$ source and $\mathrm{Ca}^{2+}$ sensor may allow modulation of the amplitude of the presynaptic $\mathrm{Ca}^{2+}$ transient by endogenous $\mathrm{Ca}^{2+}$ buffers, such as calbindin- $\mathrm{D}_{28 \mathrm{k}}[62]$.

The large size of the mossy fiber boutons and their proximal location on the apical dendrites of $\mathrm{CA} 3$ pyramidal neurons [17] suggested that the mossy fiber-CA3 pyramidal neuron synapse is a uniquely strong synapse, at least if compared to other synapses in the hippocampus. Indeed, unitary mossy fiber-CA3 pyramidal neuron EPSPs have amplitudes of 2-10 mV, and unitary EPSCs show amplitudes of up to $1 \mathrm{nA}[2,17,33,40,43]$ (Figs. 4 and 5). 
Three distinct but interrelated factors contribute to the high efficacy of this synapse. First, large boutons have a large number of release sites (37 sites, [21]; 31 sites, [1]). Second, although release probability is low under conditions of lowfrequency stimulation [48], it increases substantially during trains of stimuli, due to paired-pulse facilitation, frequency facilitation, posttetanic potentiation (PTP), and long-term potentiation (LTP; [71]). The mechanisms for the induction and expression of LTP have remained controversial, as reviewed elsewhere [64]. Finally, mossy fiber boutons contain a very large pool of releasable vesicles ("maxipool"). Capacitance measurements from hippocampal mossy fiber boutons revealed that voltage pulses that produce sustained $\mathrm{Ca}^{2+}$ inflow $(30 \mathrm{~ms}$ to $0 \mathrm{mV}$ ) evoke capacitance increases of $\sim 100 \mathrm{fF}$, corresponding to the fusion of $\sim 1,400$ vesicles [37]. Thus, the "readily releasable pool" at this synapse is large. In contrast, in the calyx of Held, a threefold larger number of vesicles $(\sim 4,000)$ is released from an approximately 20 -fold larger number of release sites $(\sim 600 ;[76,87])$. Thus, the number of releasable vesicles per release site in the mossy fiber terminal is substantially higher than in the calyx of Held. Serial electron microscopic analysis suggested that the total number of synaptic vesicles in large mossy fiber terminals is $>10,000(\sim 11,000$ small clear vesicles and $\sim 340$ large dense core vesicles in a fully reconstructed large mossy fiber bouton from a 28-day-old rat with 19 active zones; J. Lübke et al. unpublished), suggesting a large reserve pool. Both the large readily releasable pool and the huge reserve pool could be important factors to develop and maintain a high efficacy of synaptic transmission during repetitive stimulation.

\section{Differential synaptic transmission at mossy fiber-pyramidal neuron and mossy fiber-interneuron synapses}

Recent work revealed substantial differences between mossy fiber synapses on CA3 pyramidal neurons via large boutons and on stratum lucidum interneurons via filopodial extensions and small boutons $[55,80]$. First, the release probability at mossy fiber synapses on stratum lucidum interneurons is larger, while the number of release sites is smaller than at mossy fiber-CA3 pyramidal neuron synapses [48]. Second, significant differences in frequency facilitation are observed. In the mossy fiber-CA3 pyramidal neuron synapse, an increase in stimulation frequency from 0.05 to $1 \mathrm{~Hz}$ results in an $\sim 600 \%$ increase in EPSC amplitude ([71, 80]-although facilitation is less pronounced in mature synapses, [61]). In contrast, in stratum lucidum interneurons the extent of frequency facilitation is much smaller ( 200\%, [80]). Finally, marked differences in plasticity were observed. In CA3 pyramidal neurons, high- frequency stimulation (HFS) leads to a large posttetanic potentiation $(\sim 800 \%)$ and long-term potentiation $(\sim 200 \%$; $[36,68,71,88,89])$. In contrast, in stratum lucidum interneurons HFS induces synaptic depression rather than potentiation [50, 67]. Likewise, activation of the cAMP pathway by forskolin leads to a large chemical potentiation at mossy fiber-CA3 pyramidal neuron synapses [45, 82], but has only minimal effects on monosynaptic transmission at mossy fiber-stratum lucidum interneurons [55]. As synaptic plasticity at mossy fiber synapses is believed to be expressed presynaptically [64], these results suggest that the release properties of filopodial extensions and small boutons in the CA3 region differ substantially from those of large mossy fiber boutons.

However, the properties of small boutons emerging from axonal collaterals in the hilus are more similar to those of the large boutons. At the mossy fiber synapses on fast-spiking basket cells in the dentate gyrus, HFS induces both PTP and LTP [3], but the extent of plasticity at these synapses appears to be smaller than at mossy fiber-CA3 pyramidal neuron synapses [71]. For example, the extent of LTP (300 stimuli) at the mossy fiber-basket cell synapse is $133 \%$ [3], whereas it is $236 \%$ in mossy fiber-CA3 pyramidal neuron synapses [89]. Furthermore, both forskolin and phorbolesters induce a chemical potentiation of mossy fiber-dentate gyrus basket cell EPSCs [3], but again the extent of potentiation is less [239\% by $50-\mu \mathrm{M}$ forskolin; $217 \%$ by $1-\mu \mathrm{M}$ phorbol-12,13diacetate (PDA)] than that at the mossy fiber-CA3 pyramidal neuron synapse (418 and 670\%; [45]).

What is the function of differential synaptic transmission and plasticity? If granule cells fire at low frequency, the net output onto the CA3 region will be inhibitory $[1,13,14,60]$. In contrast, if granule cells fire high-frequency bursts, differential synaptic dynamics will shift the balance between monosynaptic excitation and disynaptic inhibition towards excitation. This may implement a highly nonlinear gating mechanism, by which only the granule cells with the highest activity levels relay excitation to the CA3 network.

\section{The mossy fiber synapse-a teacher synapse for completion, separation, and linkage of patterns in the dentate gyrus-CA3 cell network}

Several lines of evidence suggest that the hippocampus is involved in the processing, storage, and recall of spatial information [74]. A large proportion of granule cells in the dentate gyrus and pyramidal neurons in the CA3 and CA1 region are "place cells," showing a firing rate that is modulated by the animal's position in space [65]. It is thought that the hippocampus processes spatial information by both pattern completion (restoration of original patterns from degraded or incomplete inputs; [49]) and pattern 

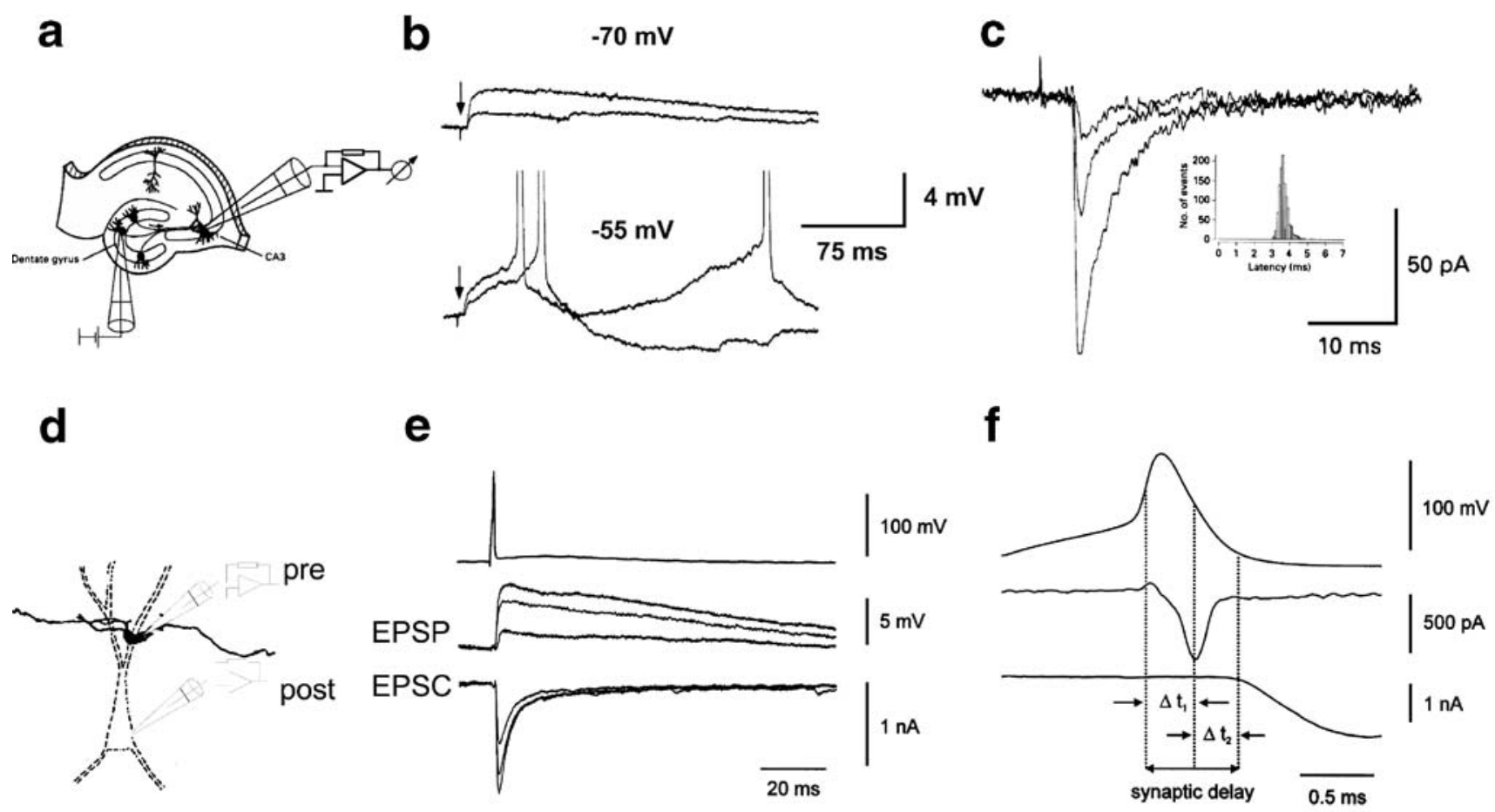

Fig. 4 Efficacy and timing of synaptic transmission at the hippocampal mossy fiber-CA3 pyramidal neuron synapse. a-c Putative unitary mossy fiber-CA3 pyramidal neuron EPSPs (b) and EPSCs (c) evoked by electrical stimulation of single granule cell somata. a Schematic illustration of the stimulation and recording method. b Unitary EPSPs evoked at $-70 \mathrm{mV}$ (close to the resting potential) or $-55 \mathrm{mV}$ (during sustained current injection). Note that unitary EPSPs trigger action potentials when the postsynaptic cell is depolarized by tonic current, suggesting that the mossy fiber-CA3 synapse acts as a conditional detonator (stimulation frequency: $1 \mathrm{~Hz}, 10 \mu \mathrm{M}$ bicuculline). c Unitary EPSCs at $-70 \mathrm{mV}$. Note that evoked transmitter release is synchronized, as expected for a single bouton with a large number of active zones. Inset, synaptic latency histogram. Data from Jonas et al. [43].

separation (amplification of differences between input patterns; [51, 52]). Experimental evidence for pattern completion is that CA3 pyramidal neurons generate consistent activity patterns after small changes in the environment [49]. Experimental evidence for pattern separation is that CA3 cells show abrupt and coordinated place field remapping when the environment is changed to a larger extent [51, $77,85]$. Finally, it is believed that the hippocampus is able to store sequences of places. Experimental support for this hypothesis is the replay of firing sequences during sleep [86] and the phenomenon of phase precession [73]. As an animal moves along a linear track, action potentials shift from late to early time points within a theta cycle, which has been interpreted as a cued and time-compressed recall of previously stored spatial information [53, 54].

How could mossy fiber synapses assist in these complex network functions? If a granule cell fires at low frequency $(<0.5 \mathrm{~Hz},[44])$, e.g., if the animal is located outside the corresponding place field, the cell is likely to have minimal d-f Unitary mossy fiber-CA3 pyramidal neuron EPSPs and EPSCs evoked by paired recording from a presynaptic mossy fiber bouton and a postsynaptic CA3 cell. d Schematic illustration of the pre- and postsynaptic recording configuration. e, Presynaptic action potential (top), unitary EPSPs (center), and unitary EPSCs (bottom). f Simultaneous recording of presynaptic action potential waveform (top), resulting $\mathrm{Ca}^{2+}$ current (center), and evoked EPSC (bottom). $\Delta t_{1}, \Delta t_{2}$ indicate components of the synaptic delay. Unitary EPSCs in the MFB-CA3 pyramidal neuron paired recordings $(\mathbf{d}-\mathbf{f})$ are larger than those in the granule cell-CA3 pyramidal neuron recordings $(\mathbf{a}-\mathbf{c})$, presumably because of bias towards large boutons in the presynaptic recordings. Data from Geiger and Jonas [33]

impact on the CA3 network because the mossy fiber-CA3 synapse is unfacilitated and inhibition will dominate over excitation $[1,13,14,60]$. In contrast, when the animal is located in a place field center (Fig. 5a; $[44,73]$ ) or during delayed nonmatch-to-sample tasks [84], granule cells will fire at higher frequencies ( $\sim 50$ and $\sim 10 \mathrm{~Hz}$, respectively), and the differential synaptic dynamics will lead to conditions in which unitary mossy fiber synaptic events trigger spikes in postsynaptic CA3 pyramidal neurons, as suggested by both in vitro and in vivo experiments [39, 40, 47, 48] (Figs. 4 and 5). Likewise, activation of the direct perforant path input onto CA3 cells (presumably signaling information about context, [53]) may lead to a scenario in which unitary mossy fiber synaptic events discharge postsynaptic CA3 pyramidal neurons, as suggested by in vitro recordings [43] (Fig. 4b). Thus, mossy fiber synapses can be viewed as "conditional detonators," discharging their postsynaptic CA3 pyramidal targets under certain conditions. Remarkably, action potentials in CA3 cells are 
a

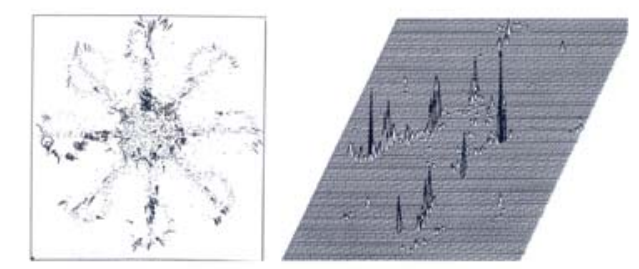

b

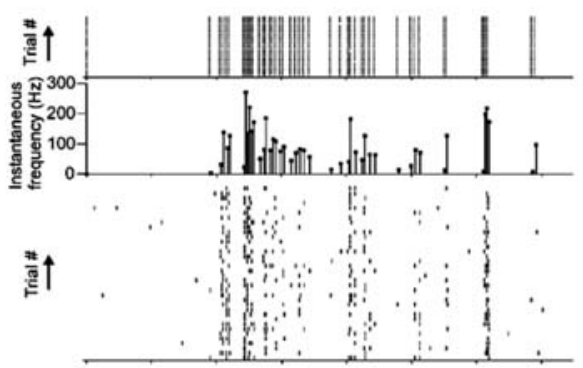

Fig. 5 The mossy fiber-CA3 pyramidal neuron synapse is a conditional detonator in vivo. a Spatial firing pattern of a granule cell in vivo at different locations in a spatial environment (eight-arm maze). Mean firing rate is plotted in a grid of $100 \times 100$ position bins. Data from Jung and McNaughton [44], with permission of Wiley, copyright (1993). b (top) Action potential pattern of an extracellularly recorded granule cell during traversal of its place field. b (center) Corresponding instantaneous action potential frequency (inverse of interspike interval). b (bottom) Raster plot of action potential activity extracellularly recorded in a CA3 pyramidal neuron while a presynaptic granule cell was stimulated intracellularly with the pattern shown in a. c Presynaptic action potentials in an intracellularly recorded granule cell (top) and postsynaptic action potentials in the synaptically

generated within a narrow time window under these conditions [40] (Fig. 5b,c), showing that detonation is conditional, but temporally precise.

The detonator function of the mossy fiber synapses has various implications for pattern completion, pattern separation, and storage of sequences of events in the hippocampal network. Mossy fiber synapses may contribute to pattern formation by acting as an unsupervised "teacher" synapse for the synaptic matrix in CA3 [54, 56, 57, 78] (Fig. 6). During storage and recall of spatial information, the role of the mossy fiber system may be envisaged as follows. (1) If an animal is located at a particular place in the environment, a subset of granule cells fires, and a subset of downstream CA3 pyramidal neurons is activated reliably via mossy fiber synapses. Additionally, information about context may be signaled via the direct perforant path input onto CA3 cells [53]. (2) If the animal visits the same place several times, the same CA3 pyramidal neuron ensemble is activated repeatedly, and the CA3-CA3 cell synapses between the neurons of the activated ensemble will be
C
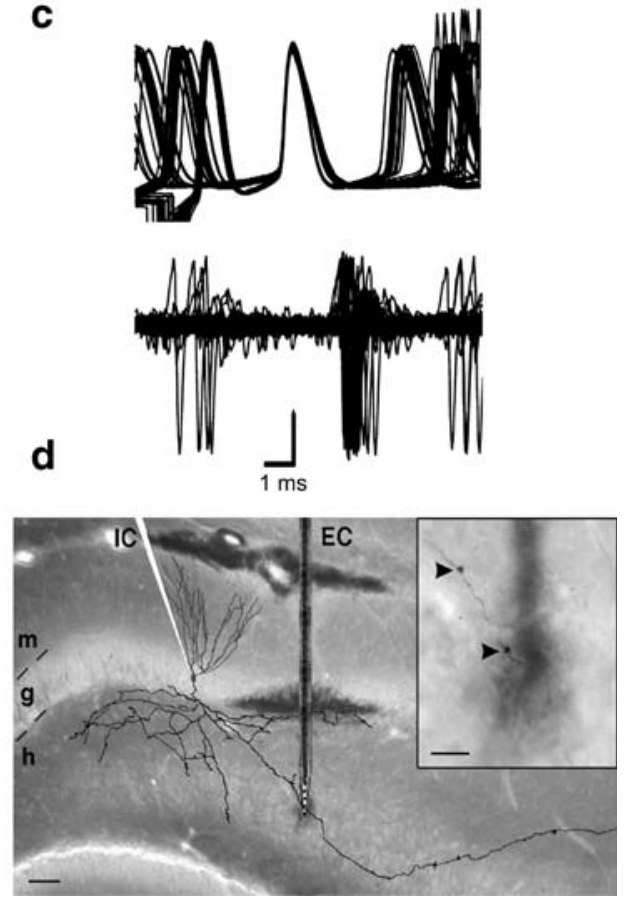

connected, extracellularly recorded CA3 pyramidal neuron (bottom). Note that bursts of three to five spikes in intracellularly recorded granule cells trigger action potentials in extracellularly recorded CA3 pyramidal neurons with high probability $(\sim 0.8)$ within a very narrow time window (standard deviation: $0.8 \mathrm{~ms}$; Henze et al. [40]). d Recording configuration for the experiments shown in $\mathbf{b}$ and $\mathbf{c}$. In vivo paired (intracellular-extracellular) recording from a granule cell and a synaptically connected CA3 pyramidal neuron. Image shows a camera lucida drawing of the presynaptic granule cell (biocytin labeled), superimposed with the hippocampal tissue. IC Intracellular electrode, $E C$ extracellular electrode, $m$ molecular layer, $g$ granule cell layer, $h$ hilus. Data from Henze et al. [40], with permission of Macmillan Publishers Ltd: Nat Neurosci, copyright (2002)

potentiated $[20,24,58]$. (3) If the animal visits the same place with a modified environment, i.e. with a partial set of cues, the potentiated CA3-CA3 synapses will enable the completion of the original pattern [54, 57, 78]. Consistent with these ideas, burst stimulation of mossy fiber inputs induces heterosynaptic LTP in CA3-CA3 cell synapses in vitro [46]. Furthermore, transgenic mice in which the NR1 N-methyl-D-aspartate (NMDA) receptor subunit gene is specifically deleted in CA3 pyramidal neurons show decreased memory performance in a partial-cue, but not in a full-cue environment [63].

Additionally or alternatively, the mossy fiber pathway could contribute to pattern separation $[66,78]$. The sparse connectivity between dentate gyrus granule cells and CA3 pyramidal neurons [4] and the differential dynamics of mossy fiber synapses on pyramidal neurons, which facilitate markedly, and those on interneurons, which facilitate less or even depress [80], may implement a "winner takes all" mechanism in which only the most active granule cells relay excitation to the CA3 network. Computational studies 


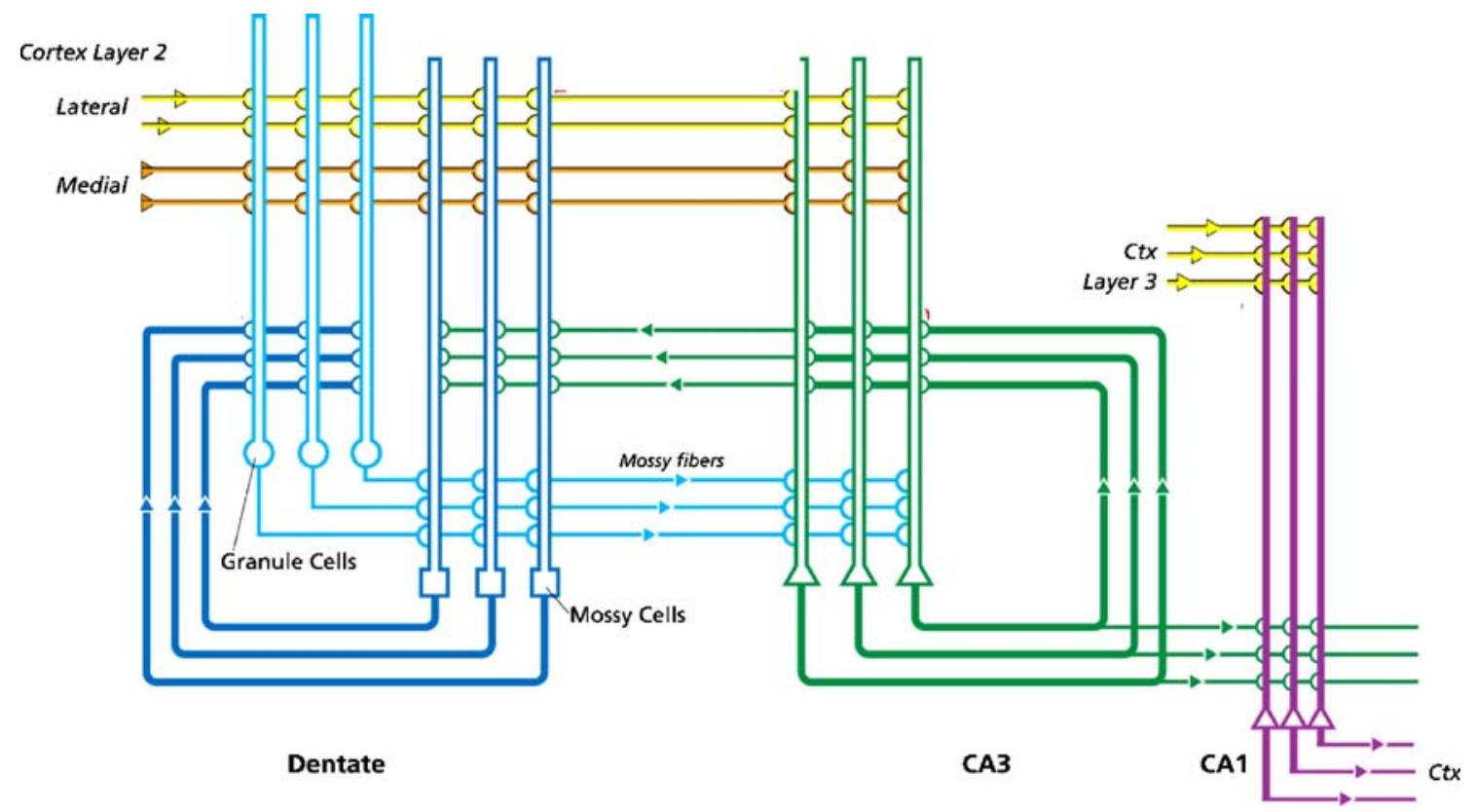

Fig. 6 Role of the mossy fiber pathway in storage and recall of episodic memory in autoassociative and heteroassociative networks. Granule cells and mossy fiber axons forming mossy fiber-CA3 cell synapses are drawn in cyan. CA3 pyramidal cells and their collaterals forming CA3-CA3 cell synapse are drawn in green. Hilar mossy cells are drawn in blue. The input from the perforant path to granule cells and CA3 cells is shown on top. The output to the CA1 region is shown at the bottom. Scheme kindly provided by John Lisman [53]. Storage of information may be envisaged as follows: when the animal is exposed to an episode (i.e., a series of items), subpopulations of granule cells encoding items $1,2,3, \ldots$ are activated sequentially. Activation of granule cells is thought to occur via a multi-item buffer (presumably in associative cortical areas), which may activate granule cells repeatedly in a time-compressed manner via the perforant path $[53,54]$, rather than directly by sensory input. The mossy fiber pathway relays the activation of the subpopulations of granule cells encoding for item $1,2,3, \ldots$ to corresponding subpopulations of CA3 cells. Because of the Hebbian properties of CA3-CA3 pyramidal cell synapses, information about individual items could be stored as an increase in synaptic strength in the autoassociative CA3 network. The excitatory polysynaptic excitatory loop granule cells-CA3 pyramidal cells-mossy cells-granule cells "plays back" the original granule cell activity to the granule cell layer with a time delay (e.g., due to axonal conduction). Thus, the activation of granule cells corresponding to item 2 will coincide with the played-back signal originally generated by item 1 . Because of the Hebbian synaptic properties, the link between the two items could be stored as an increase in synaptic strength in the heteroassociative granule cell network, e.g., in mossy cell-granule cell synapses [53, 54]. Recall of information may be envisaged as follows. If an animal is reexposed to item 1 or a partial version of it, this activates the subpopulation of granule cells encoding item 1. Additionally, the excitatory polysynaptic loop granule cellsCA3 pyramidal cells-mossy cells-granule cells is activated. Within this loop, the autoassociative CA3 cell network helps to complete the original pattern. The completed pattern is then played back to the granule cell layer, where it may activate the subpopulation of granule cells encoding item 2 via potentiated synapses, e.g., mossy cellgranule cell synapses. Thus, the network may be able to 'predict' future events suggested that pattern separation can be implemented by this mechanism [66]. In such a model, regulation of the strength of the mossy fiber-CA3 pyramidal neuron synapse, e.g., by non-Hebbian frequency facilitation, PTP, or LTP, could set the balance between pattern completion and pattern separation [66].

Finally, mossy fiber synapses may also help to establish heteroassociative links between individual items in a sequence, such as series of places [9] (Fig. 6). It was proposed that heteroassociative links are established in the dentate gyrus [54]. To link two consecutive items by spike timing-dependent plasticity, the action potentials encoding the first item need to be "played back" to the granule cells at a time point matching the activity period corresponding to the second item. This would require a connection among granule cells, e.g., by the polysynaptic excitatory pathway granule cell $\rightarrow$ CA3 pyramidal neuron $\rightarrow$ mossy cell $\rightarrow$ granule cell [54] (Fig. 6). If action potentials corresponding to subsequent items in a sequence were separated by a time interval corresponding to a gamma oscillation cycle ( $20 \mathrm{~ms}$; [54]), the polysynaptic granule cell $\rightarrow$ CA3 pyramidal neuron $\rightarrow$ mossy cell $\rightarrow$ granule cell pathway would need to relay activity back precisely within $20 \mathrm{~ms}$. The unique anatomical and functional properties of the mossy fiber axon, including reliable action potential propagation, precisely tuned presynaptic $\mathrm{Ca}^{2+}$ signaling and transmitter release, and large impact on target cells under certain conditions, appears to be an ideal design to implement such a reliable and temporally precise delay line [27]. 
Acknowledgements We thank Beat Gähwiler, Liyi Li, and Chris McBain for comments on an earlier version of the manuscript. This work was supported by grants of Deutsche Forschungsgemeinschaft (SFB 505/C9 to J.B., SFB 505/C5, C12, and Leibniz program to P.J.) and the Bundesministerium für Bildung und Forschung (OI GQ 0420).

\section{References}

1. Acsády L, Kamondi A, Sik A, Freund T, Buzsáki G (1998) GABAergic cells are the major postsynaptic targets of mossy fibers in the rat hippocampus. J Neurosci 18:3386-3403

2. Alle H, Geiger JRP (2006) Combined analog and action potential coding in hippocampal mossy fibers. Science 311:1290-1293

3. Alle H, Jonas P, Geiger JRP (2001) PTP and LTP at a hippocampal mossy fiber-interneuron synapse. Proc Natl Acad Sci USA 98:14708-14713

4. Amaral DG, Ishizuka N, Claiborne B (1990) Neurons, numbers and the hippocampal network. Prog Brain Res 83:1-11

5. Bischofberger J, Geiger JRP, Jonas P (1999) Presynaptic $\mathrm{Ca}^{2+}$ channels in hippocampal mossy fiber boutons. Society for Neuroscience abstracts 25, 502.2

6. Bischofberger J, Geiger JRP, Jonas P (2002) Timing and efficacy of $\mathrm{Ca}^{2+}$ channel activation in hippocampal mossy fiber boutons. J Neurosci 22:10593-10602

7. Bishop GH (1965) My life among the axons. Annu Rev Physiol 27:1-18

8. Blackstad TW, Kjaerheim A (1961) Special axo-dendritic synapses in the hippocampal cortex: electron and light microscopic studies on the layer of mossy fibers. J Comp Neurol 117:133-146

9. Blum KI, Abbott LF (1996) A model of spatial map formation in the hippocampus of the rat. Neural Comput 8:85-93

10. Borst JGG, Sakmann B (1996) Calcium influx and transmitter release in a fast CNS synapse. Nature 383:431-434

11. Borst JGG, Sakmann B (1999) Effect of changes in action potential shape on calcium currents and transmitter release in a calyx-type synapse of the rat auditory brainstem. Philos Trans R Soc Lond B Biol Sci 354:347-355

12. Borst JGG, Helmchen F, Sakmann B (1995) Pre- and postsynaptic whole-cell recordings in the medial nucleus of the trapezoid body of the rat. J Physiol 489:825-840

13. Bragin A, Jandó G, Nádasdy Z, Hetke J, Wise K, Buzsáki G (1995a) Gamma (40-100 Hz) oscillation in the hippocampus of the behaving rat. J Neurosci 15:47-60

14. Bragin A, Jandó G, Nádasdy Z, van Landeghem M, Buzsáki G (1995b) Dentate EEG spikes and associated interneuronal population bursts in the hippocampal hilar region of the rat. J Neurophysiol 73:1691-1705

15. Brandt A, Khimich D, Moser $\mathrm{T}$ (2005) Few $\mathrm{Ca}_{\mathrm{V}} 1.3$ channels regulate the exocytosis of a synaptic vesicle at the hair cell ribbon synapse. J Neurosci 25:11577-11585

16. Breustedt J, Vogt KE, Miller RJ, Nicoll RA, Schmitz D (2003) $\alpha_{1 E^{-}}$containing $\mathrm{Ca}^{2+}$ channels are involved in synaptic plasticity. Proc Natl Acad Sci USA 100:12450-12455

17. Brown TH, Johnston D (1983) Voltage-clamp analysis of mossy fiber synaptic input to hippocampal neurons. J Neurophysiol 50:487-507

18. Caldwell JH, Schaller KL, Lasher RS, Peles E, Levinson SR (2000) Sodium channel $\mathrm{Na}_{\mathrm{v}} 1.6$ is localized at nodes of Ranvier, dendrites, and synapses. Proc Natl Acad Sci USA 97:5616-5620
19. Castillo PE, Weisskopf MG, Nicoll RA (1994) The role of $\mathrm{Ca}^{2+}$ channels in hippocampal mossy fiber synaptic transmission and long-term potentiation. Neuron 12:261-269

20. Chattarji S, Stanton PK, Sejnowski TJ (1989) Commissural synapses, but not mossy fiber synapses, in hippocampal field CA3 exhibit associative long-term potentiation and depression. Brain Res 495:145-150

21. Chicurel ME, Harris KM (1992) Three-dimensional analysis of the structure and composition of CA3 branched dendritic spines and their synaptic relationships with mossy fiber boutons in the hippocampus. J Comp Neurol 325: $169-182$

22. Cooper EC, Milroy A, Jan YN, Jan LY, Lowenstein DH (1998) Presynaptic localization of Kv1.4-containing A-type potassium channels near excitatory synapses in the hippocampus. J Neurosci 18:965-974

23. Debanne D (2004) Information processing in the axon. Nat Rev Neurosci 5:304-316

24. Debanne D, Gähwiler BH, Thompson SM (1998) Long-term synaptic plasticity between pairs of individual CA3 pyramidal cells in rat hippocampal slice cultures. J Physiol 507:237-247

25. de Polavieja GG, Harsch A, Kleppe I, Robinson HP, Juusola M (2005) Stimulus history reliably shapes action potential waveforms of cortical neurons. J Neurosci 25:5657-5665

26. Edwards FA, Konnerth A, Sakmann B, Takahashi T (1989) A thin slice preparation for patch clamp recordings from neurones of the mammalian central nervous system. Pflügers Arch 414:600-612

27. Engel D, Jonas P (2005) Presynaptic action potential amplification by voltage-gated $\mathrm{Na}^{+}$channels in hippocampal mossy fiber boutons. Neuron 45:405-417

28. Forsythe ID (1994) Direct patch recording from identified presynaptic terminals mediating glutamatergic EPSCs in the rat CNS, in vitro. J Physiol 479:381-387

29. Frotscher M (1985) Mossy fibres form synapses with identified pyramidal basket cells in the CA3 region of the guinea-pig hippocampus: a combined Golgi-electron microscope study. J Neurocytol 14:245-259

30. Frotscher M (1996) Synaptic transmission. In: Greger R, Windhorst $U$ (eds) Comprehensive human physiology. Springer, Berlin Heidelberg New York, pp 321-334

31. Frotscher M, Soriano E, Misgeld U (1994) Divergence of hippocampal mossy fibers. Synapse 16:148-160

32. Gasparini S, Kasyanov AM, Pietrobon D, Voronin LL, Cherubini E (2001) Presynaptic R-type calcium channels contribute to fast excitatory synaptic transmission in the rat hippocampus. J Neurosci 21:8715-8721

33. Geiger JRP, Jonas P (2000) Dynamic control of presynaptic $\mathrm{Ca}^{2+}$ inflow by fast-inactivating $\mathrm{K}^{+}$channels in hippocampal mossy fiber boutons. Neuron 28:927-939

34. Geiger JRP, Bischofberger J, Vida I, Fröbe U, Pfitzinger S, Weber HJ, Haverkampf K, Jonas P (2002) Patch-clamp recording in brain slices with improved slicer technology. Pflügers Arch 443:491-501

35. Gollasch M, Hescheler J, Quayle JM, Patlak JB, Nelson MT (1992) Single calcium channel currents of arterial smooth muscle at physiological calcium concentrations. Am J Physiol 263: C948-C952

36. Griffith WH (1990) Voltage-clamp analysis of posttetanic potentiation of the mossy fiber to CA3 synapse in hippocampus. J Neurophysiol 63:491-501 
37. Hallermann S, Pawlu C, Jonas P, Heckmann M (2003) A large pool of releasable vesicles in a cortical glutamatergic synapse. Proc Natl Acad Sci USA 100:8975-8980

38. Hamill OP, Marty A, Neher E, Sakmann B, Sigworth FJ (1981) Improved patch-clamp techniques for high-resolution current recording from cells and cell-free membrane patches. Pflügers Arch 391:85-100

39. Henze DA, Urban NN, Barrionuevo G (2000) The multifarious hippocampal mossy fiber pathway: a review. Neuroscience 98:407-427

40. Henze DA, Wittner L, Buzsáki G (2002) Single granule cells reliably discharge targets in the hippocampal CA3 network in vivo. Nat Neurosci 5:790-795

41. Hille B (2001) Ion channels of excitable membranes. Sinauer, Sunderland, Massachusetts

42. Hodgkin AL, Huxley AF (1952) A quantitative description of membrane current and its application to conduction and excitation in nerve. J Physiol (Lond) 117:500-544

43. Jonas P, Major G, Sakmann B (1993) Quantal components of unitary EPSCs at the mossy fibre synapse on CA3 pyramidal cells of rat hippocampus. J Physiol (Lond) 472:615-663

44. Jung MW, McNaughton BL (1993) Spatial selectivity of unit activity in the hippocampal granular layer. Hippocampus 3:165-182

45. Kamiya H, Yamamoto C (1997) Phorbol ester and forskolin suppress the presynaptic inhibitory action of group-II metabotropic glutamate receptor at rat hippocampal mossy fibre synapse. Neuroscience 80:89-94

46. Kobayashi K, Poo MM (2004) Spike train timing-dependent associative modification of hippocampal CA3 recurrent synapses by mossy fibers. Neuron 41:445-454

47. Lawrence JJ, McBain CJ (2003) Interneuron diversity series: containing the detonation-feedforward inhibition in the CA3 hippocampus. Trends Neurosci 26:631-640

48. Lawrence JJ, Grinspan ZM, McBain CJ (2004) Quantal transmission at mossy fibre targets in the CA3 region of the rat hippocampus. J Physiol (Lond) 554:175-193

49. Lee I, Yoganarasimha D, Rao G, Knierim JJ (2004) Comparison of population coherence of place cells in hippocampal subfields CA1 and CA3. Nature 430:456-459

50. Lei S, McBain CJ (2002) Distinct NMDA receptors provide differential modes of transmission at mossy fiber-interneuron synapses. Neuron 33:921-933

51. Leutgeb S, Leutgeb JK, Treves A, Moser MB, Moser EI (2004) Distinct ensemble codes in hippocampal areas CA3 and CA1. Science 305:1295-1298

52. Leutgeb S, Leutgeb JK, Barnes CA, Moser EI, McNaughton BL, Moser MB (2005) Independent codes for spatial and episodic memory in hippocampal neuronal ensembles. Science 309: 619-623

53. Lisman JE (1999) Relating hippocampal circuitry to function: recall of memory sequences by reciprocal dentate-CA3 interactions. Neuron 22:233-242

54. Lisman JE, Talamini LM, Raffone A (2005) Recall of memory sequences by interaction of the dentate and CA3: a revised model of the phase precession. Neural Netw 18:1191-1201

55. Maccaferri G, Tóth K, McBain CJ (1998) Target-specific expression of presynaptic mossy fiber plasticity. Science 279:1368-1370

56. Marr D (1971) Simple memory: a theory for archicortex. Philos Trans R Soc Lond B Biol Sci 262:23-81

57. McNaughton BL, Morris RGM (1987) Hippocampal synaptic enhancement and information storage within a distributed memory system. Trends Neurosci 10:408-415
58. Miles R, Wong RK (1986) Excitatory synaptic interactions between CA3 neurones in the guinea-pig hippocampus. J Physiol 373:397-418

59. Miyazaki K, Ishizuka T, Yawo H (2005) Synapse-to-synapse variation of calcium channel subtype contributions in large mossy fiber terminals of mouse hippocampus. Neuroscience 136: 1003-1014

60. Mori M, Abegg MH, Gähwiler BH, Gerber U (2004) A frequency-dependent switch from inhibition to excitation in a hippocampal unitary circuit. Nature 431:453-456

61. Mori-Kawakami F, Kobayashi K, Takahashi T (2003) Developmental decrease in synaptic facilitation at the mouse hippocampal mossy fibre synapse. J Physiol 553:37-48

62. Müller A, Kukley M, Stausberg P, Beck H, Müller W, Dietrich D (2005) Endogenous $\mathrm{Ca}^{2+}$ buffer concentration and $\mathrm{Ca}^{2+}$ microdomains in hippocampal neurons. J Neurosci 25:558-565

63. Nakazawa K, Quirk MC, Chitwood RA, Watanabe M, Yeckel MF, Sun LD, Kato A, Carr CA, Johnston D, Wilson MA, Tonegawa S (2002) Requirement for hippocampal CA3 NMDA receptors in associative memory recall. Science 297:211-218

64. Nicoll RA, Schmitz D (2005) Synaptic plasticity at hippocampal mossy fibre synapses. Nat Rev Neurosci 6:863-876

65. O'Keefe J, Dostrovsky J (1971) The hippocampus as a spatial map. Preliminary evidence from unit activity in the freely-moving rat. Brain Res 34:171-175

66. O'Reilly RC, McClelland JL (1994) Hippocampal conjunctive encoding, storage, and recall: avoiding a trade-off. Hippocampus 4:661-682

67. Pelkey KA, Lavezzari G, Racca C, Roche KW, McBain CJ (2005) mGluR7 is a metaplastic switch controlling bidirectional plasticity of feedforward inhibition. Neuron 46:89-102

68. Regehr WG, Delaney KR, Tank DW (1994) The role of presynaptic calcium in short-term enhancement at the hippocampal mossy fiber synapse. J Neurosci 14:523-537

69. Rhodes KJ, Strassle BW, Monaghan MM, Bekele-Arcuri Z, Matos MF, Trimmer JS (1997) Association and colocalization of the $\operatorname{Kv} \beta 1$ and $\operatorname{Kv} \beta 2 \beta$-subunits with $\operatorname{Kv1} \alpha$-subunits in mammalian brain $\mathrm{K}^{+}$channel complexes. J Neurosci 17: $8246-8258$

70. Ruiz A, Fabian-Fine R, Scott R, Walker MC, Rusakov DA, Kullmann DM (2003) $\mathrm{GABA}_{\mathrm{A}}$ receptors at hippocampal mossy fibers. Neuron 39:961-973

71. Salin PA, Scanziani M, Malenka RC, Nicoll RA (1996) Distinct short-term plasticity at two excitatory synapses in the hippocampus. Proc Natl Acad Sci USA 93:13304-13309

72. Schmitz D, Schuchmann S, Fisahn A, Draguhn A, Buhl EH, Petrasch-Parwez E, Dermietzel R, Heinemann U, Traub RD (2001) Axo-axonal coupling: a novel mechanism for ultrafast neuronal communication. Neuron 31:831-840

73. Skaggs WE, McNaughton BL, Wilson MA, Barnes CA (1996) Theta phase precession in hippocampal neuronal populations and the compression of temporal sequences. Hippocampus $6: 149-172$

74. Squire LR, Stark CE, Clark RE (2004) The medial temporal lobe. Annu Rev Neurosci 27:279-306

75. Stuart GJ, Dodt H-U, Sakmann B (1993) Patch-clamp recordings from the soma and dendrites of neurons in brain slices using infrared video microscopy. Pflügers Arch 423:511-518

76. Sun JY, Wu LG (2001) Fast kinetics of exocytosis revealed by simultaneous measurements of presynaptic capacitance and postsynaptic currents at a central synapse. Neuron 30: $171-182$ 
77. Vida I, Frotscher M (2000) A hippocampal interneuron associated with the mossy fiber system. Proc Natl Acad Sci USA 97:1275-1280

78. Treves A, Rolls ET (1992) Computational constraints suggest the need for two distinct input systems to the hippocampal CA3 network. Hippocampus 2:189-200

79. Tong G, Malenka RC, Nicoll RA (1996) Long-term potentiation in cultures of single hippocampal granule cells: a presynaptic form of plasticity. Neuron 16:1147-1157

80. Toth K, Suares G, Lawrence JJ, Philips-Tansey E, McBain CJ (2000) Differential mechanisms of transmission at three types of mossy fiber synapse. J Neurosci 20:8279-8289

81. Vida I, Frotscher M (2000) A hippocampal interneuron associated with the mossy fiber system. Proc Natl Acad Sci USA 97:1275-1280

82. Weisskopf MG, Castillo PE, Zalutsky RA, Nicoll RA (1994) Mediation of hippocampal mossy fiber long-term potentiation by cyclic AMP. Science 265:1878-1882

83. Westenbroek RE, Merrick DK, Catterall WA (1989) Differential subcellular localization of the $\mathrm{R}_{\mathrm{I}}$ and $\mathrm{R}_{\mathrm{II}} \mathrm{Na}^{+}$channel subtypes in central neurons. Neuron 3:695-704
84. Wiebe SP, Stäubli UV (1999) Dynamic filtering of recognition memory codes in the hippocampus. J Neurosci 19: 10562-10574

85. Wills TJ, Lever C, Cacucci F, Burgess N, O'Keefe J (2005) Attractor dynamics in the hippocampal representation of the local environment. Science 308:873-876

86. Wilson MA, McNaughton BL (1994) Reactivation of hippocampal ensemble memories during sleep. Science 265:676-679

87. Wölfel M, Schneggenburger R (2003) Presynaptic capacitance measurements and $\mathrm{Ca}^{2+}$ uncaging reveal submillisecond exocytosis kinetics and characterize the $\mathrm{Ca}^{2+}$ sensitivity of vesicle pool depletion at a fast CNS synapse. J Neurosci 23:7059-7068

88. Yeckel MF, Kapur A, Johnston D (1999) Multiple forms of LTP in hippocampal CA3 neurons use a common postsynaptic mechanism. Nat Neurosci 2:625-633

89. Zalutsky RA, Nicoll RA (1990) Comparison of two forms of long-term potentiation in single hippocampal neurons. Science 248:1619-1624 